\title{
К вопросу о создании политомического компьютерного ключа для определения растений семейства Ranunculaceae Juss.
}

\section{To the question of creating a polytomic computer key to determine plants family of the Ranunculaceae Juss.}

\author{
Новолодский И. В. \\ Novolodsky I. V. \\ Бурятский государственный университет имени Д. Банзарова, г. Улан-Удэ, Россия. E-mail: novolodskii.igor96@mail.ru \\ Buryat State University, Ulan-Ude, Russia
}

Peферат. В наше время существует множество проблем, которые встают перед исследователями при изучении растений, такие как систематизация, деление на таксономические единицы (семейство, род, вид и др.) и идентификация как гербарных образцов, так и свежего материала. В данной работе рассматривается создание политомических ключей и их использование в определителях на примере семейства Ranunculaceae Juss. a та же написание программ-определителей на их основе.

Ключевые слова. Матрицы определения, политомический ключ, Республика Бурятия, семейство Ranunculaceae Juss., электронный определитель.

Summary. Nowadays, there are many problems that researchers face when studying plants, such as: systematization, division into taxonomic units (family, genus, species, etc.) and identification of both herbaric samples and fresh material. This paper discusses the creation of polytomic keys and their use in identification on the example of the family Ranunculaceae Juss. as well as writing identification programs based on them.

Key words. Definition matrixes, polytomical key, republic of Buryatia, family Ranunculaceae Juss., electronic determinant.

\section{Введение}

Семейство Ranunculaceae Juss. является одним из узловых в большинстве филогенетических систем цветковых растений (Зиман,1984). Разнообразие морфоструктур вегетативных и генеративных органов у представителей семейства и их различная эволюционная продвинутость делает данное семейство интересным объектом исследования (Новолодский, 2017). Несмотря на большую потребность в определителях, они редко печатаются и еще реже переиздаются. Подавляющее большинство построено на основе дихотомического ключа. Политомическая организация определителя в печатном варианте встречается единично.

\section{Материалы и методы}

В качестве модельного объекта для создания определителя и конвертации матриц определения в политомические ключи, нами было выбрано семейство Ranunculaceae. Сборы образцов проводились в различных районах республики с использованием детально-маршрутного метода, позволяющего наиболее полно выявить разнообразие растительности и ее пространственное размещение. В ходе работы был собран гербарный материал в количестве 350 листов, были использованы образцы гербария кафедры ботаники Бурятского государственного университета им. Д. Банзарова (г. Улан-Удэ) и Центрального сибирского ботанического сада СО РАН (г. Новосибирск). Критически проанализированы систематические признаки 23 родов, входящих в состав семейства. Созданы графические определительные таблицы и матрицы, которые стали основой для авторских политомических ключей. 
При составлении данных ключей нами были выделены следующие этапы:

1. Описание и кодирование: выбор признаков, приведение их в сравнимую форму и объединение в ряды (групповые признаки). Ряд признаков в политомическом ключе представляет собой аналог тезы (антитезы) в дихотомическом, однако при политомической организации определителя исключается возможность перекрывания вариантов признаков, т. к. в его основе лежат альтернативные, взаимоисключающие варианты. Это обеспечивает большую надежность диагноза.

2 . Составление графических определительных систем для упрощения процесса апробации и выявления также возможных основных недочетов (рис. 1).

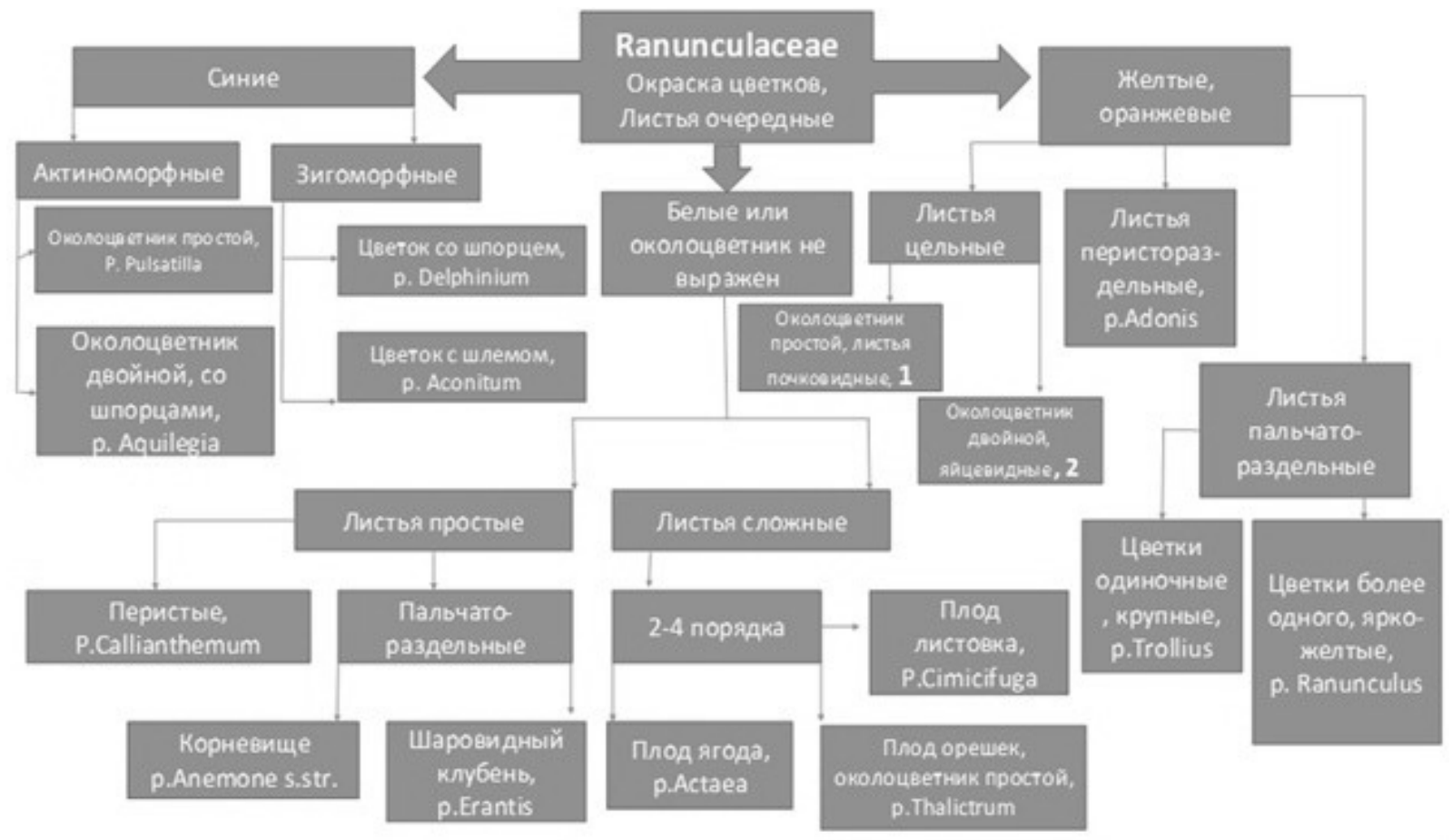

Рис.1. Графическая определительная система семейства Ranunculaceae Республики Бурятии.

3. Составление матриц определения, в которых содержатся все признаки таксона (табл.).

4. Разработка и апробация логической структуры определителя, которая позволяет выявить логические ошибки и неточности в работе программы. Логическая структура также наглядно показывает ход определения растения (рис. 2).

5. Создание баз данных. Базы данных можно рассматривать как новый этап развития традиционных библиотек. Основной проблемой при создании баз данных является организация разнородной информации в удобном для конечного пользователя виде, что требует новых исследований и разработок пользовательских интерфейсов для корректного отражения предметной области (Антопольский, 2007).

Для реализации проекта был использован язык WEB-программирования: HTML. Проектирование архитектуры и реализация базы данных велись в среде Data base SQLite и Microsoft Access, программная оболочка реализована на языках HTML и PHP.

В настоящей работе представлены оригинальные скриншоты работы с программой. Вёрстка проекта осуществлялась средствами HTML. Раздел «Определение вида» содержит панель признаков, которая автоматически генерируется на основе информации из выбранной базы данных, а так же содержит перечень видов, представленных в базе (рис. 3). Автоматизирован вывод признаков на основе типов данных: качественные признаки выводятся с помощью раскрывающегося списка, где возможен выбор только одного из вариантов; количественные признаки отображаются в виде полей ввода, куда необходимо ввести их значения; и признаки с множественным выбором параметров, где возможен вы- 
бор более одного варианта. К каждому виду прилагается ботаническое описание, а также подробные фотографии диагностических признаков (рис 4).

Матрица определения рода Pulsatilla Mill.

\begin{tabular}{|l|c|c|c|c|c|c|c|c|c|c|c|c|c|c|}
\hline \multicolumn{1}{|c|}{ Название вида } & 1 & 2 & 3 & 4 & 5 & 6 & 7 & 8 & 9 & 10 & 11 & 12 & 13 & 14 \\
\hline P. flavescens (Zucc.) Juz. & + & + & - & - & + & - & - & - & + & + & + & + & - & - \\
\hline P. multifida (Pritz.) Juz. & + & + & - & + & - & - & + & + & + & - & + & + & - & - \\
\hline P. angustifolia Turcz. & + & + & + & + & - & - & + & - & + & - & + & - & + & - \\
\hline P. tenuiloba (Turcz.) Juz. & - & + & + & + & - & - & + & + & - & - & + & + & - & + \\
\hline $\begin{array}{l}\text { P. dahurica } \text { (Fisch. Ex } \\
\text { DC.) Spreng. }\end{array}$ & - & + & + & + & - & + & + & + & - & - & + & + & - & + \\
\hline $\begin{array}{l}\text { P. ajanensis Regel \& } \\
\text { Tiling }\end{array}$ & - & + & + & + & - & + & + & + & - & + & - & - & + & + \\
\hline $\begin{array}{l}\text { P. ambigua (Turcz. ex } \\
\text { Hayek) Juz. }\end{array}$ & - & + & + & + & - & + & + & + & - & + & - & + & - & + \\
\hline $\begin{array}{l}\text { P. turczaninovii Krylov } \\
\text { \& Serg. }\end{array}$ & - & + & + & + & - & + & + & + & - & + & - & + & - & + \\
\hline
\end{tabular}

Примечание: знаком +/- отмечено наличие или отсутствие признака. Диагностические признаки: 1) прикорневые листья пальчатые; 2) прикорневые листья рассеченные; 3) листья перистые; 4) цветки сине-фиолетовые; 5) цветки желтые; 6) пластинки прикорневых листьев широкие; 7) прикорневые листья округлые; 8) прикорневые листья яйцевидные; 9) прикорневые листья узкие; 10) ости плодиков утолщены; 11) ости плодиков тонкие;12) цветки колокольчатые; 13) цветки широко раскрытые 14) перистые листья.

\section{Группы родовыхпризнаков}

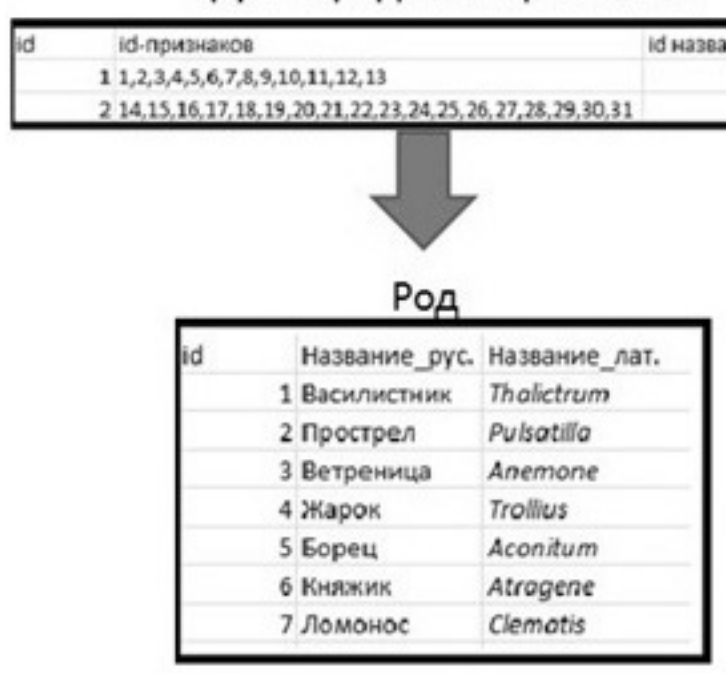

Группы видовыхпризнаков

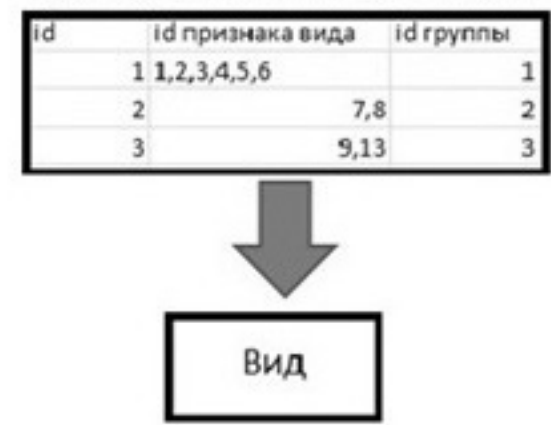

\section{Родовые признаки}

\begin{tabular}{|c|}
\hline Название \\
\hline 1 Циеток актиноморффный \\
\hline 2 Циеток виғоморфмовй \\
\hline 3 цееток со шпорцем. \\
\hline 4 Цветки белье \\
\hline S цеетия желтые \\
\hline 6 Цеетия синие \\
\hline 7 Leetrat kpacroie \\
\hline 8 цеети фиолетовье \\
\hline 9 цеетки оранкевье \\
\hline 10 цеети 6леднолиновые \\
\hline 11 Цுeетicoe 1.3 \\
\hline 12 Многоцветковое растение \\
\hline 13 Циеты өсегда одимочные \\
\hline
\end{tabular}

\section{Видовые признаки}

\begin{tabular}{|c|c|c|}
\hline id & id poдa & Назеание \\
\hline 1 & & 1 กлодики сидячие \\
\hline 2 & & 1 Плодики по ре6рам крылатые \\
\hline 3 & & 1 Плодики голые \\
\hline 4 & & 1 плодики спиосснутые \\
\hline 5 & & 1 Плодики опушеные \\
\hline 6 & & 1 กлодик на короткой ножке \\
\hline 7 & & 1 Тонкие тылиночные нити \\
\hline 8 & & 1 Тычиночные мити утопценяые \\
\hline 9 & & 1 Соцветие метелка \\
\hline 10 & & 1 Растение ronoe \\
\hline 11 & & 1 Характерный неприятный запах \\
\hline 12 & & 1 Растение опушенье \\
\hline 13 & & 1 Соцветие простая кисть \\
\hline
\end{tabular}

Рис.2. Фрагмент логической структуры определителя. 


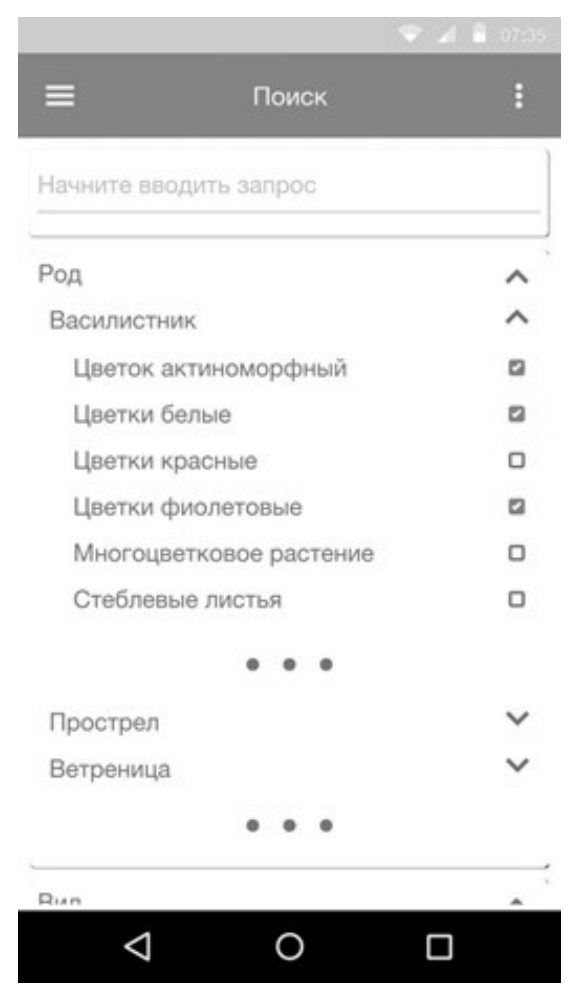

Рис.3. Определение вида.

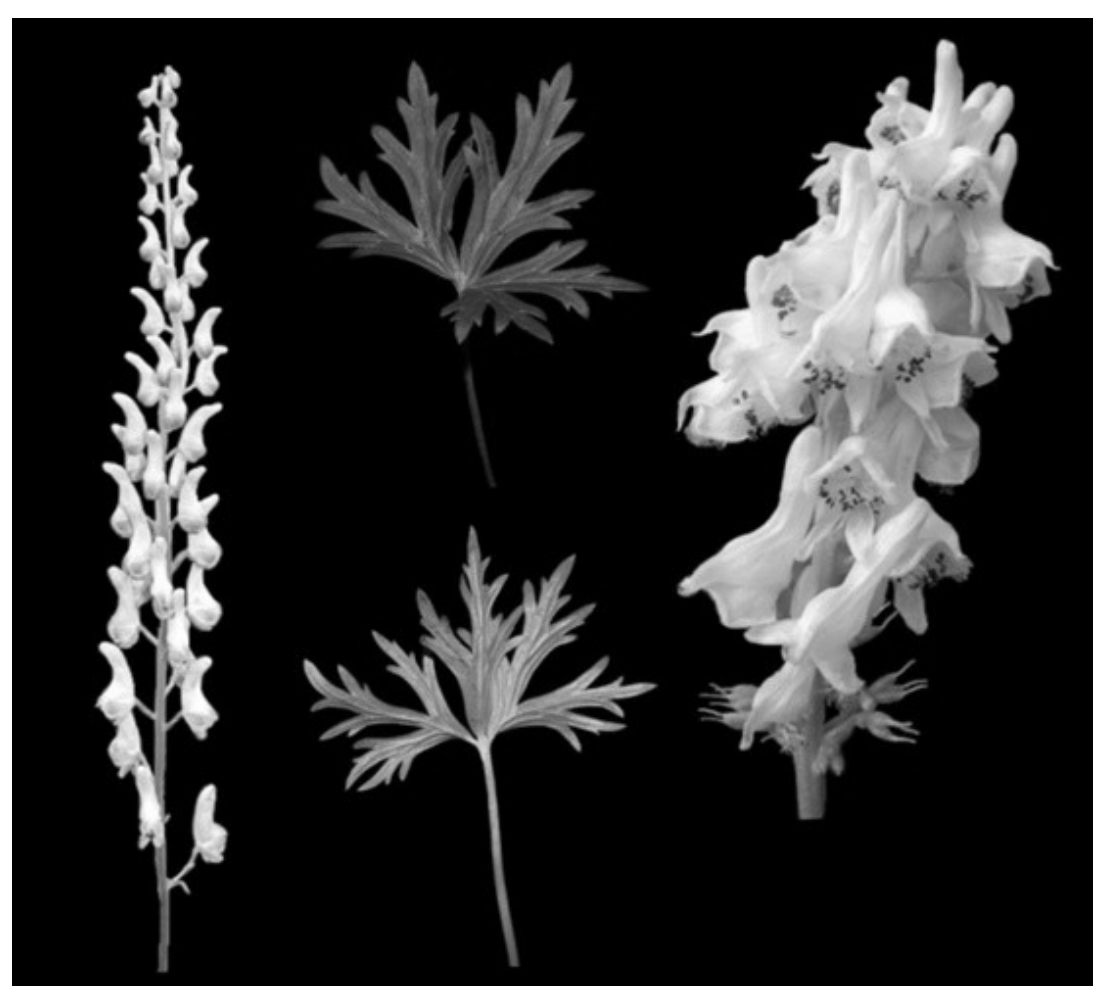

Рис.4. Диагностические виды.

Критический анализ признаков семейства Ranunculaceae позволяет утверждать, что данное семейство обладает огромным разнообразием морфоструктур вегетативных и генеративных органов у представителей семейства, а приизрастание на территории Республики Бурятии видов, относящихся к большинству родов и представляющих основные морфотипы, позволяло экстраполировать данные полученные при анализе признаков на политомические ключи и электронную программу.

Благодарности. Автор выражает благодарность научному руководителю к.б.н., доценту кафедры ботаники БГУ Пыжиковой Евгении Михайловне за помощь в подготовке работы и ценные указания и консультации.

\section{ЛИТЕРАТУРА}

Aнтопольский A. Б. Электронные библиотеки: принципы создания / А. Б. Антопольский, Т. В. Майстрович // Серия «Библиотекарь и время. XXI век». - М.: Изд-во Либерея-Бибинформ, 2007. - Вып. №56. - 283 с.

Зиман С.H. Морфологическая эволюция семейства Лютиковые (Ranunculaceae Juss.). - Киев, 1984. - 404 с.

Новолодский И. В. Определительная система родов семейства Ranunculaceae Juss. республики Бурятия // Meжрегиональная молодежная науч.-практ. конф. «Растительный мир Байкальской природной территории: современное состояние и перспективы исследования». - Улан-Удэ, 2014. - С. 30-32. 